\title{
The Relationship between Linguistics and Language Teaching
}

\author{
Jing Meng \\ College of foreign languages, Qingdao University of Science and Technology \\ Qingdao 266061, China \\ E-mail: laserain@163.com
}

\begin{abstract}
The problem of linguistics in language teaching has been discussed for many years in SLA. Researchers try to find out the relationship between linguistics and language teaching. In this paper, the author gives her own opinion about their relationship on the basis of some linguists' theories and attempts to show the implication of linguistic theories on the practice of language teaching.
\end{abstract}

Keywords: Language, Linguistics, Language teaching

\section{Introduction}

The beginning of the research of the relationship between linguistic theory and language teaching can be traced back to the late of $19^{\text {th }}$ century. From then on different research proposed by different scholars has been disputable. Until 1960s, when their relationship was reassessed, emerged two viewpoints: one was to say that linguistics is not so important as it has been thought, i.e. its importance had been overrated. Some linguists like Johnson (1967) and Lamendella (1969) expressed their disagreement to regard linguistics as the basis of a strategy of learning. Lamendella (1969) thought that it was a mistake to look to transformational grammar or any other theory of linguistic description to provide the theoretical basis for second language pedagogy. What is needed in the field of language teaching are not applied linguists but rather applied psychologists. The other point of view was to recognize the general contribution of linguistics but with the proviso that language teaching is not bound to abide consistently by one theory. Different linguistic theories can offer different perspectives on language, and they can be treated as equivalent resources. Levenson (1979) once said, "no one school of linguistic analysis has a monopoly of truth in the description of the phenomena of speech...traditional school grammar, TG grammar, ... all these and more can be shown to have their own particular relevance to the language teaching situation.' I agree to the second point of view. In my opinion, linguistics and language teaching are interactional with each other. In this paper, all the language teaching, teaching theories or language pedagogy refer to $\mathrm{L} 2$ teaching.

According to my knowledge, the relationship of linguistic theory and language teaching is a dual one. It means, on the one hand, some theories of linguistics can be applied to language teaching, i.e. linguistics guides the development of language teaching theory. On the other hand, a language teaching theory expresses or implies answers to questions about the nature of language. These questions relate language teaching theory directly to theoretical linguistics.

\section{How linguistics guides language teaching or language pedagogy?}

Early in the years of Second World War, linguistics was recognized as an important component in language teaching theory. During the Second World War, America was in great need of soldiers knowing foreign languages. To meet this demand, a group of linguists including Bloomfield (1942) undertook to use the knowledge of linguistics to analyze the language to be taught and the result proved to be satisfactory. Bloomfield suggested that the only effective teacher should be the trained linguist working alongside the students, because language teachers often have an insufficient command of the language, only the trained linguists know how to guide the students learning from native speakers and how to teach the forms of the language. In my opinion, Bloomfield's suggestion looks a little extreme, but we must admit that as a language teacher we must have a good command of the knowledge of linguistics, in that case can we teach well. For example, in teaching pronunciation, if we know phonetics well, we can tell the students the construction of our organs of articulation and how a sound is produced by the cooperation of the organs. We can also help the students obtain the knowledge of how to classify the vowel and consonant and how to produce a sound accurately with the correct position of the tongue. Only have a good master of phonetics can the students learn word pronunciation well. So the language teachers must adopt the phonetician's analysis of speech sounds and the International Phonetic 
Alphabet for pronunciation training.

By about 1960, the influence of structural linguistics upon language teaching had reached a peak in the United States. Structural linguistics stressed the importance of language as a system and investigates the place that linguistic units such as sounds, words, sentences have within this system. In association with behaviorism it provided the principal theoretical basis of the audio lingual theory and in this way influence language teaching materials, techniques and teacher education.

Behaviorism led to theories of language teaching and learning which explained how an external event (a stimulus) caused a change in the behavior of an individual (a response) without any kind of mental behavior. Though Behaviorism neglected the mental activity, it stressed the importance of practice and repetition in language learning, which in my opinion is a vital factor in learning a foreign language. Let's take the audiolingual method as an example. Audiolingual method emphasizes: (1) the teaching of speaking and listening before reading and writing; (2) the use of dialogues and drills; (3) the avoidance of the use of the mother tongue in the classroom. Audiolingual method regards speaking and listening as the most basic language skills, which is in accordance with our today's English teaching situation. Nowadays, in China, more and more people begin to learn English as a foreign language in order to have the ability to communicate with foreigners. For them, speaking and listening is much more important than reading and writing because they are not expected to have a high mastery of English and their aim of study is quite simple, that is when they need to communicate with a foreigner they can understand their words and express themselves well. Of course, what we are talking about is based on simple daily conversation, because to express ourselves properly is not always an easy thing, even for English major students sometimes it is problematic.

In China, we begin to teach students English when they are in primary school. In the past, we paid more attention on teaching them grammar, and the result was disappointing: a large number of students cannot speak well; some even cannot say a complete sentence. Recently we emphasized the importance of speaking and listening in English teaching and adopted audiolingual method in the classroom. Audiolingual method stressed the practice and repetition of what has been learnt in the classroom; it believes that a language is learnt through forming habits. I agree with it. In order to speak English fluently, without constant practice, it is impossible. So in our English teaching and learning, we must do a lot of work to help our students speak and listen well whenever they need to use it.

While the influence of structuralism on language teaching and pedagogy was pervasive and powerful, the influence of TG grammar was of a different kind. In the late sixties, new developments in language pedagogy occurred which can be regarded as resulting from the impact of TG theory. A typical example is the cognitive theory of language learning. This theory emerged in which TG concepts became associated with a 'cognitive' view of the psychology of language learning. It opposed to the empiricist theory, that is, pedagogically audiolingualism, psychologically behaviorism, and linguistically structuralism. TG theory stressed mental activity. It proposed that human beings have the ability to learn a language. It is the inborn ability instead of practice that made human beings obtain the rules of a language and understand or produce countless numbers of sentences. Some linguists, like Diller (1970), openly declared his preference for the cognitive position; while others, like Chastain (1976) and Rivers (1981:25-27) held that the two theories were complementary and served different types of learners or teachers or represented different phases of the language learning process. In my opinion, I agree with the second point of view. I believe that empiricist theory is useful for our language teaching and learning; while cognitive theory is more useful for linguists, i.e. for linguistic analysis.

In 1970s, a group of scholars including Oller (1970) and Widdowson (1978), who were linguists in their own right but at the same time closely in touch with teaching practice, gave language teaching and language pedagogy the linguistic direction they regarded as necessary. Since they were in a good position to create a link between linguistic theory and language teaching practice, they placed emphasis on real language use. Let's take Oller's interest in pragmatics as an example. Oller (1970:507) claimed that pragmatics has implications for language teaching; it defines the goal of teaching a language as prompting the students not merely to manipulate meaningless sound sequences, but to send and receive messages in the language. Through my own experience in English teaching and learning, I find out that to grasp some knowledge of pragmatics can indeed help us teach or learn English well. For instance, in daily conversation, people often speak in an indirect way, maybe we have noticed it, but without the knowledge of pragmatics, we cannot give a correct explanation for it. With the knowledge of pragmatics we can explain some language phenomena clearly and accurately, thus make our students have a deeper insight into the nature of language.

Widdowson (1978) defined a set of contrasting concepts which distinguish language as a formal system and language use as communicative events. He advocated shifting the emphasis from teaching a second language as a formal system to teaching a second language as communication. Widdowson's point of view is in accordance with our L2 teaching situation. Recently we stressed the importance of students' communicative abilities (that are saying, listening and talking etc.) instead of their linguistic skills. This does not mean we need not the knowledge of linguistics; on the contrary, we use the linguistic theory as a guide for our language teaching. 


\section{Linguistics Language Teaching and the Nature of Language}

Language is an inherently complex system. It presents some contradictions and oppositions. Both linguistics and language teaching must consider these contradictions; otherwise they cannot provide a satisfactory solution to the problems of language.

Since language is complex by nature, what linguistics has to do is to identify the elements or aspects in order to analyze it. For example, when we talk about a language we try to analyze it from four aspects: sound system, grammatical system, lexical system and discourse system. We may ask which aspect does our language teaching practice or teaching theory include or exclude. Theoretically speaking, all these four aspects should be involved in our teaching theory, because they constitute a whole picture of language. When we analyze each aspect, we will use linguistic theory to describe it, that means we have to consider how does it work linguistically; what does it mean semantically and how is it used sociolinguistically. Only when a language is analyzed systematically can it be learnt practically. However, language teachers wish to teach language as a whole, that means language should be regarded as a synthesis in our teaching practice. So a satisfactory language teaching theory should consider the language both as isolated features and as a synthesis.

There is another opposition in language, that is, language is both rule-governed and creative. It involves order and regularity, but it also provides opportunity to be creative. Upon this fact, the language teaching practice or teaching theory as well as the linguistic theory must take into account the regularities and the possibility of making use of the regularities in varied ways. In our teaching practice, we should teach the students the grammar or the rules of a language; while on the other hand, we may let the students use language innovatively based on these rules. In my opinion, the teaching of the rules should be put at the highest position, because without a solid foundation of the English language it is hard to imagine how students will effectively communicate at high levels.

Because of the intricacies a language possesses, we cannot ask a language teaching theory to cover all the aspects of a language. Since it is impossible for a theory of language to do justices to the whole of a language, all language teaching theories have to sacrifice some aspects of language in order to highlight others. Though linguistics cannot present us a definite interpretation of language, it can help us to think critically and constructively about language, which makes possible the design of the most feasible and practical language teaching pedagogy.

\section{Conclusion}

The dual relationship between linguistics and language teaching is important for language pedagogy. The continuing developments in linguistic theory and in language teaching theory as well as the constant changes in the language itself demand the permanent study of language and the relations between linguistic theory and language teaching or language pedagogy.

\section{References}

Bloomfield, L. (1942). Outline Guide for the Practical Study of Foreign Languages. Special Publications of the Linguistic Society of America. Baltimore: Linguistic Society of America.

Chastain, K. (1976). Developing Second-Language Skills: Theory to Practice. Chicago: Rand McNally.

Diller, K.C. (1970). 'Linguistic theories of language acquisition' in Hester 1970:1-32.

Johnson, M. (1967). Definitions and models in curriculum theory. Educational Theory, 17:127-40.

Lamendella, J.T. (1969). On the irrelelevance of transformational grammar to second language pedagogy. Language Learning, 19:255-70.

Levenson, E.A. (1979). Second language lexical acquisition: issues and problems. Interlanguage Studies Bulletin, 4:147-60.

Oller, J.W. (1970). Transformational theory and pragmatics. Modern Language Journal, 54:504-507.

Rivers, W.M. (1981). Teaching Foreign-Language Skills. Second edition. Chicago and London: University of Chicago Press.

Widdowson, H.G.. (1978). Teaching Language as Communication. Oxford: Oxford University Press. 